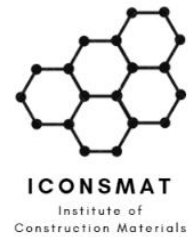

Content list available at ICONSMAT

Journal of Construction Materials

Journal homepage: www.iconsmat.com.au/publication
Article history:

Received 19 March 2021

Received in revised form

2 April 2021

Accepted 2 April 2021

Available online

4 April 2021

\title{
Evaluation of environmental, technical, and economic indicators of a fused deposition modelling process
}

\author{
Mazyar Yosofi*1 ${ }^{*}$, Sonia Ezeddini ${ }^{1}$, Anaïs Ollivier ${ }^{2}$, Valérie Lavaste ${ }^{3}$, Céline Mayousse ${ }^{2}$ \\ ${ }^{1}$ ALTRAN Ouest, 3 Rue Louis Braille, 35136 Saint-Jacques-de-la-Lande, France \\ ${ }^{2}$ ALTRAN Ouest, 1 impasse Charles Trenet, 44800 Saint-Herblain, France \\ ${ }^{3}$ ALTRAN Research \& Innovation Direction, 2 rue Paul Dautier, 78140 Vélizy-Villacoublay, France \\ *Corresponding author: Phone: +33 0681178473; E: Mazyar.yosofi@altran.com
}

\begin{abstract}
Additive manufacturing processes have changed significantly in a wide range of industries and their application progressed from rapid prototyping to production of end-use products. However, their environmental impact is still a rather open question. In order to support the growth of this technology in the industrial sector, environmental aspects should be considered and predictive models may help monitor and reduce the environmental footprint of the processes. This work presents predictive models based on a previously developed methodology for the environmental impact evaluation combined with a technical and economical assessment. Here we applied the methodology to the Fused Deposition Modelling process. First, we present the predictive models relative to different types of machines. Then, we present a decision-making tool designed to identify the optimum manufacturing strategy regarding technical, economic, and environmental criteria.
\end{abstract}

DOI: 10.36756/JCM.v2.3.7 C2021 Institute of Construction Materials

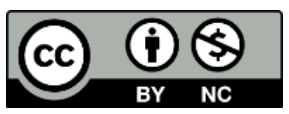

\section{Keywords}

Additive manufacturing; Decision making; Environmental impact; Predictive modelling 


\section{Introduction}

Additive manufacturing (AM) technologies evolved significantly over the last few decades resulting in major technical advances. Initially restricted to the manufacture of prototype parts, AM is now a fullyfledged manufacturing process offering capabilities for functional part production [1]. AM processes have been used in industry for a long time, and plenty of research has been conducted on aspects of process control and product quality [2]. The same goes for the cost of these processes [3]. These processes are often described as clean processes, as they only use the exact amount of material needed to build functional parts, thus limiting waste, which makes it a good alternative to reduce the environmental impact compared to conventional processes such as machining. Nowadays, environmental footprint consideration during the manufacturing step of a part has become an important issue in our society [4]. In the near future, the choice of machines or processes that will minimize environmental impacts will be more common.

Environmental analysis of AM processes is based on multiple criteria. For many years, even after the first studies regarding the environmental aspects of AM processes [5], electrical energy consumption was the only consumption source studied in the literature. These studies were oriented towards the definition of the specific energy consumption (SEC) [6]. The SEC is the amount of energy consumed in kWh for 1 kilogram of processed materials.

Mognol et al. [7] studied the influence of part orientation on the SEC values for three AM processes: powder bed fusion, material jetting and material extrusion. They showed that it is possible to achieve a substantial energy (43-61\%) saving by choosing the set of parameters that will minimize the height of the part.

Baumers et al. [8] explored the SEC by studying the effect of packing density of the space machine and part geometry on the electrical energy consumption of powder bed fusion and material extrusion processes. They determined that the SEC decreased when multiple parts are manufactured on the same time [9].

Junk and Côté [10] studied the effect of the part placement on the build platform on the electrical energy consumption for material extrusion and material jetting processes. They found that the SEC is lower when the part is manufactured near the machine zero point [11].

Other studies on the SEC of AM processes are reported in [12]-[14]. Thus, the SEC is no longer sufficient as soon as we need to predict the electrical energy consumption of AM processes. Therefore, it is necessary to set up predictive models in order to consider all the manufacturing parameters of the part. Based on the inventory data presented previously, various authors developed parametric models for AM processes in order to estimate the environmental impact and related environmental footprint during the manufacturing step.

Baumers et al. developed models that estimate the electrical energy consumption and the costs occurring during the manufacturing of the part with an accuracy of $+/-10 \%$ for powder bed fusion process (EOSINT M270 DMLS system). They concluded that cost minimization in AM leads to the minimization of electrical energy consumption [15].

LeBourhis et al. presented a method to evaluate the environmental impact of direct energy deposition process using direct additive laser manufacturing technology [16]. Based on both analytic and experimental models and using the computer-aided design (CAD) model with the energy and resource consumption, the authors estimated the related environmental impact. 
$\mathrm{Xu}$ et al. developed a model that calculates the total energy consumption of binder jetting process during the manufacturing step [17]. The authors took into account the electrical energy with layer thickness, part geometry and part orientation. Energy demands of the curing and sintering step should be included in the study in order to quantify the total environmental impact of the process.

Kellens et al. developed a parametric process model to estimate the environmental impact of powder bed fusion processes using selective laser sintering technology with PA2200 and PA3200GF polymer materials [18]. The models are based on the volume and the total build height of the part. Their models estimated total electrical energy and resource consumption as well as the environmental impact [19]. Yosofi et al. presented a method which makes it possible to obtain energy models for AM processes [20]. For a high precision energy consumption prediction, they divided the manufacturing process into different stages and obtain the energy consumption of each stage through experiment with an accuracy of $+/-10 \%$. They applied their methodology on multiple AM processes: material extrusion, material jetting and powder bed fusion [21].

These studies have improved knowledge around the environmental footprints of AM. However, there is still a lack of information for some processes. Indeed, more research must be done in order to fulfill the life cycle inventory database for AM. Nevertheless, it is possible to predict information thanks to parametric models and therefore to make a choice of process or machine. However, making a choice of process from an environmental point of view is not representative of the industry. Indeed, choosing a process rather than another in the industrial sector is mainly governed by the feasibility and the cost price. That is why it is important to combine environment information with technical and economic information.

AM techniques have been applied in various domains, such as the aerospace, automotive and biomedical industries. Nowadays, many works can be found on the mechanical properties of the parts made by AM processes. The first studies were focused on the influence of processes parameters on the flexural properties [22]-[25]. These studies led to work on improving these processes by reducing build time [26], material consumption and part weight [27]. Many authors have developed predictive models to determine the mechanical properties before the part production. Carneiro et al. developed a parametric model to estimate the tensile strength of ABS parts made by material extrusion processes [28]. Other studies on ABS can be found in [29]-[32]. Since the main defect of these processes is poor surface condition, Boschetto et al. developed parametric models of surface quality indicators in order to predict the surface roughness of parts made by the material extrusion process [33], [34].

Cost estimation for AM processes has evolved from rather crude initial models [35] to more accurate estimates [36]. The late models tend to consider all the activities involved in AM in order to calculate the full cost of a finished part [37].

All this work on improving these processes is a sign of the latter's technical and economic maturity. Some authors work on the linkage between technical and cost criteria [38] or environmental and cost criteria [39]. However, more research needs to be done in order to continue in multicriteria evaluation of AM processes [40]. This manufacturing process had also shown many outstanding results in various spectrums of industries particularly in the construction industry [41-47] and extra-terrestrial construction [48-58]. However, in terms of financing this new innovative construction technology there has been many financial barriers observed which also studied to be effectively addressed by the utilization of blockchain technology [59-67].

This paper therefore presents predictive models using a methodology in order to evaluate three material extrusion machines from a technical, economic and environmental point of view. The remainder of this paper is divided into three sections. Section II describes the current status of the state 
of the art regarding the multicriteria evaluation of AM processes. Section III explains the methodology used in this study. Finally, Section IV presents the application of the methodology on a use case.

\section{Methodology}

The applied methodology, described in detail by Yosofi et al. [40], consists to evaluate AM processes from a technical, economic and environmental point of view (Fig. 1). Its purpose is to enable manufacturers to choose between different manufacturing processes or machines based on multiple criteria. The methodology is decomposed of two major steps. First, all the data needed to create the models are collected. The authors proposed accurate models, leveraged on experimental measurements for the electrical energy consumption. They break down the process into different manufacturing stages to make a power study of each stage. Subsequently, a time study is performed in order to calculate the total electrical energy consumption. Simple models are presented regarding fluid and material consumption. Empirical formulae for cost models and equations for the technical model are extracted from the literature. These models allow consumption flows to be predicted for parts of any shape.

Once all the different data have been acquired, either directly from the literature or the process, it is possible to create the different predictive models related to the technical characteristics, cost, and inventory data of the machine used. All the acquired data are entered in a numerical tool developed in Visual Basic Application (VBA). The models can be used by entering the following data provided by the CAD or slicing software:

- Layer height;

- Manufacturing angles;

- Preprocess duration;

- Postprocess duration;

- Part volume;

- Density of material used.

Finally, in step two, the different consumption flows are simultaneously displayed in a single graph. More information about the experimental protocol and method for obtaining the different models are available in [21]. In this paper, the methodology has been applied on three machines of the material extrusion process:

- $\quad$ Prusa i3 MK3S

- Ultimaker 3

- Ultimaker 2 Go 
Step 1:Data acquistion

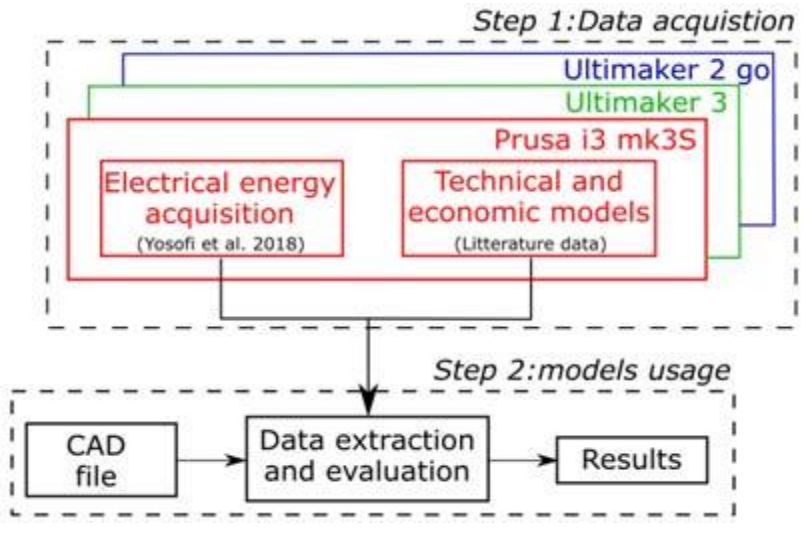

Figure 1 - The two steps of the methodology

\section{Result and discussion}

The evaluation of AM processes focused on consumption (inventory data) during the part manufacturing. In the case of AM processes, the flows are split into three categories:

- Electrical energy,

- Material consumption,

- Compressed air and water consumption and waste.

The methodology does not take the machine's particle emissions into account nor does it consider the material and energy used to manufacture the machine tool, material, part, or machine tool recycling. However all the data on this consumption should be considered in any lifecycle analysis.

\section{A. Machines Studied}

The methodology has been applied on three material extrusion machines. The Prusa I3 MK3S, the Ultimaker 3 and the Ultimaker 2 Go. Fig. 2 shows the three machines studied.

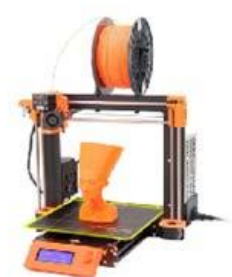

Prusa i3 mk3s

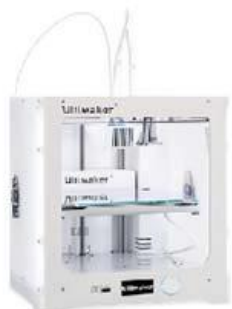

Ultimaker 3

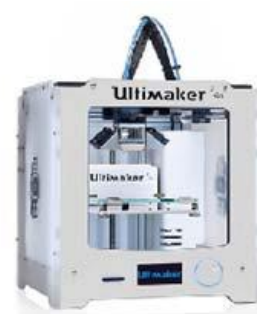

Ultimaker 2 go

Figure 2 - Machines studied.

\section{B. Parametric Model of the Electrical Energy Consumption}

Breaking the process down into its various stages makes it possible to have a generic formula for the total consumption of electrical energy during the production of a part (1). The total electrical energy consumption is equal to the sum of the electrical energy consumed during each stage.

$E_{\text {total }}=E_{\text {Idling }}+E_{\text {Preparation }}+E_{\text {Forming }}+E_{\text {Postprocess }}$ 
Where $E_{\text {Idling }}$ is the electrical energy associated with the idling stage, $E_{\text {Preparation }}$ is the electrical energy associated with the preparation stage, $E_{F o r m i n g}$ is the electrical energy associated with the forming stage, and $E_{\text {Postprocess }}$ is the electrical energy associated with the postprocess stage. Electrical energy measurements are performed with an energy analyzer (Voltracft 4000f).

Table 1 shows the measured average power and average duration of each stage of each machine.

Table 1 - Average power and duration of each stage

\begin{tabular}{|c|c|c|c|c|c|c|c|c|}
\hline Machine & $P_{\text {idling }}(W)$ & $\begin{array}{l}\text { P Plate } \\
\text { preparation } \\
(\mathrm{W})\end{array}$ & $\begin{array}{c}\text { P Plate temp } \\
\text { maintenance } \\
(\mathrm{W})\end{array}$ & $\begin{array}{c}\mathrm{P}_{\text {Head }} \\
\text { preparation } \\
(\mathrm{W})\end{array}$ & $\begin{array}{l}\mathrm{P}_{\text {Head temp }} \\
\text { maintenance } \\
(\mathrm{W})\end{array}$ & $P_{\text {Forming }}(w)$ & $\begin{array}{c}\text { TPlate } \\
\text { preparation }(\mathrm{s})\end{array}$ & $\begin{array}{c}\mathrm{T}_{\text {Head }} \\
\text { preparation } \\
(\mathrm{s}) \\
\end{array}$ \\
\hline Prusa i3 MK3S & 8.1 & 146.6 & 34.7 & 25.1 & 11.6 & 48.6 & 124.2 & 78 \\
\hline Ultimaker 3 & 5.31 & 139 & 47.8 & 16.6 & 1.37 & 35 & 181.1 & 76.9 \\
\hline Ultimaker 2 Go & 4.25 & 0 & 0 & 58.8 & 0 & 74.8 & 0 & 67.8 \\
\hline
\end{tabular}

Table 2 presents the parametric electrical energy models for the three machines. In this table, Tpreparation is the sum of $T$ Plate preparation and $T_{\text {Head preparation. }} T_{\text {Total }}$ is total duration estimated by the slicing software.

Table 2 - Parametric models of the electrical energy consumption of each machine

\begin{tabular}{ll}
\hline \hline Machine & Electrical energy consumption \\
\hline Prusa i3 MK3S & $\mathrm{E}_{\text {total }}=\left(8.10 \times \mathrm{T}_{\text {total }}\right)+(146.6 \times 124.2)+(25.1 \times 78)+\left[(34.7+11.6+48.6) \times\left(\mathrm{T}_{\text {total }}-\mathrm{T}_{\text {preparation }}\right)\right]$ \\
Ultimaker 3 & $\mathrm{E}_{\text {total }}=\left(5.31 \times \mathrm{T}_{\text {total }}\right)+(139 \times 181.1)+(16.7 \times 76.9)+\left[(47.8+1.37+35) \times\left(\mathrm{T}_{\text {total }}-\mathrm{T}_{\text {preparation }}\right)\right]$ \\
Ultimaker 2 Go & $\mathrm{E}_{\text {total }}=\left(4.25 \times \mathrm{T}_{\text {total }}\right)+(58.8 \times 67.8)+\left[74.8 \times\left(\mathrm{T}_{\text {total }}-\mathrm{T}_{\text {preparation }}\right)\right]$ \\
\hline \hline
\end{tabular}

\section{Parametric Models for Resource Consumption}

An empirical equation (2) is used to predict the total amount of material used during the process. The total material consumption is the sum of the materials needed for the part and the support.

M total $=(\rho$ Part x VPart $)+(\rho$ Support $x$ VSupport $)$

where $\rho$ Part is the material density of the part, VPart is the volume of the part, $\rho$ Support is the material density of the support, and VSupport the volume of the support. For these studied machines, there is no need of fluid consumption. Support material is removed manually from the part.

\section{Technical and Economic Model}

Technical model to predict the arithmetic roughness is the same used by Yosofi et al. [20]. However, for the economic model, we consider also the price of the electrical consumption that is 0.15 Euros/kWh.

Fig. 3 presents the studied part of $105 \times 100 \times 55$ mm made in PLA polymer. This part represents a support for the surgical mask to move the mask away from the mouth. This part requires more support material than the part himself. The manufacturing angle of the top of the part is $90^{\circ}$. 


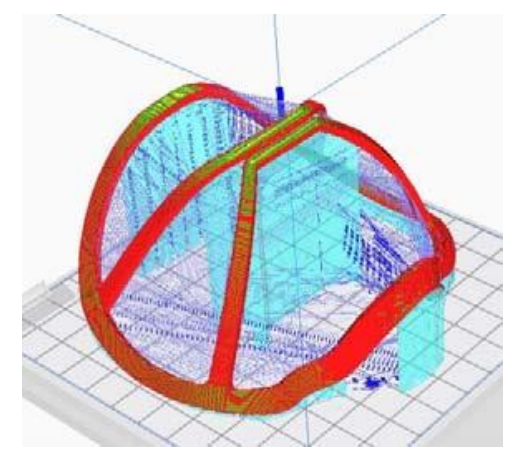

Figure 3 - COVID mask

\section{E. Results}

In order to compute all information about the different models obtained by data measurements or extracted from the literature, we designed a numerical tool. It allows the user to enter initial data and compare the results for each pair of machines in order to determine quickly the best one that suits them.

Table 3 shows the input values for the part studied. All the information is obtained thanks to the CAD and slicing software. Table 4 indicates the estimated values by the models.

Table 3 - Input values of the part studied.

\begin{tabular}{cccccccc}
\hline \hline Equipment & Part & $\begin{array}{c}\text { Layer } \\
\text { height } \\
(\mathrm{mm})\end{array}$ & Infill (\%) & $\begin{array}{c}\text { Part volume } \\
\left(\mathrm{cm}^{3}\right)\end{array}$ & $\begin{array}{c}\text { Support } \\
\text { volume } \\
\left(\mathrm{cm}^{3}\right)\end{array}$ & $\begin{array}{c}\text { Estimated } \\
\text { time }(\mathrm{min})\end{array}$ & $\begin{array}{c}\text { Real time } \\
(\mathrm{min})\end{array}$ \\
\hline Prusa i3 MK3S & & 0.3 & & 10.4 & 14.6 & 238 & 253 \\
Ultimaker 3 & $\begin{array}{c}\text { COVID } \\
\text { mask }\end{array}$ & 0.2 & 100 & 6.4 & 6.4 & 183 & 172 \\
Ultimaker 2 Go & & 0.2 & & 6.4 & 6.4 & 127 & 127 \\
\hline \hline
\end{tabular}

Table 4 - Output values (estimated values)

\begin{tabular}{ccccccc}
\hline \hline Equipment & Energy (Wh) & $\begin{array}{c}\text { Cost } \\
\text { (Euros) }\end{array}$ & Ra $(\mu \mathrm{m})$ & Part weight $(\mathrm{g})$ & $\begin{array}{c}\text { Support } \\
\text { weight }(\mathrm{g})\end{array}$ & $\begin{array}{c}\text { SEC } \\
(\mathrm{kWh} / \mathrm{kg})\end{array}$ \\
\hline Prusa i3 MK3S & 406 & 4.01 & 25.6 & 13.1 & 17.8 & 13.1 \\
Ultimaker 3 & 248 & 6.79 & 17.2 & 14 & 8 & 11.3 \\
Ultimaker 2 Go & 169 & 3.41 & 17.2 & 14 & 8 & 7.7 \\
\hline \hline
\end{tabular}

Table 5 shows the estimated and the real values of the electrical energy consumption with de deviation for each machine.

Fig. 4 illustrates the combination of the estimated results for the three material extrusion machines. To have an exploitable result curve, we created a system of value scaling by calculating the percentage of each result related to the largest. Since the part studied is the same for the three machines, material consumption and arithmetic roughness are also the same. 
Table 5 - Deviation between estimated and real energy consumption

\begin{tabular}{cccc}
\hline \hline Equipment & $\begin{array}{c}\text { Estimated energy } \\
\text { consumption (Wh) }\end{array}$ & $\begin{array}{c}\text { Real energy } \\
\text { consumption (Wh) }\end{array}$ & Deviation (\%) \\
\hline Prusa i3 MK3S & 406 & 385 & 5 \\
Ultimaker 3 & 248 & 223 & 10 \\
Ultimaker 2 Go & 169 & 153 & 8 \\
\hline \hline
\end{tabular}

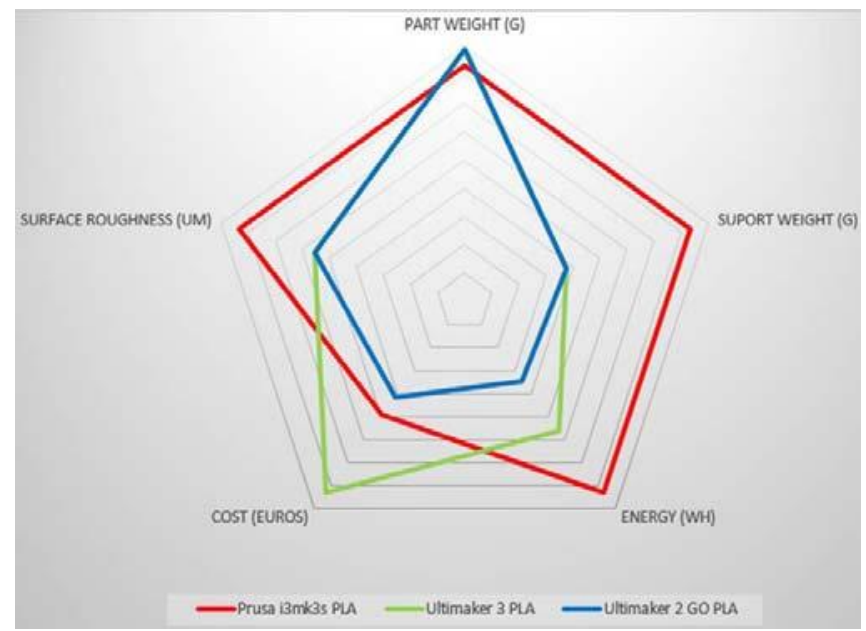

Figure 4 - Estimated results of the three machines

\section{F. Discussion}

Recording the energy consumption of the manufacturing process stage by stage, over several cycles of repetition made it possible to gain accurate models of electrical energy consumption. We measured the electrical energy consumption during the manufacturing of the part and the deviation between the model and measured values, as shown in Table V. We observe that deviation for the Prusa i3 MK3S and the Ultimaker 2 Go is less than 10\%. The Ultimaker 3 has a deviation of $10 \%$ between the two electrical energy values. These deviations are due to the precision of the measuring device which has an impact on the precision of the models and in addition to the difference between the estimated time and the real manufacturing time. This way of presenting the results (Fig. 4) enables a user to make a choice of machine or process according to the criteria he wishes to highlight.

From an environmental point of view, the Ultimaker $2 \mathrm{Go}$ is the ideal machine because it consumes less energy and support material. The difference of part weight between the two Ultimaker machines and the Prusa machine is 0.9 grams, which is negligible. This part made by the Ultimaker 2 Go will cost less than the other two.

Finally, the arithmetic roughness for the two Ultimaker machines is lower than the Prusa i3 MK3S. We can conclude that for this specific part, the ideal machine is the Ultimaker $2 \mathrm{Go}$. However, in order to have a more accurate study, it would be interesting to have a part quality indicator. Indeed, in our case, the model estimates that the Ultimaker $2 \mathrm{Go}$ is the more appropriate solution. Nevertheless, parts printed with this machine have the poorest visual appearance of the three. Thus, future work will focus on adding indicators to support decision making, the study of other materials and include more technical indicators (yield strength, tensile strength). 


\section{Conclusion}

In this paper, the authors propose a technical, economic and environmental evaluation of three machines of the material extrusion process. The methodology used is based on both analytic models (validated by experiments) and experimental models. The work concerning the inventory data is not only focused on electrical consumption but also on resources consumption which also contributes to the environmental impact. These environmental aspects are then coupled with technical and cost properties in order to have a multicriteria evaluation allowing a user to have a global view of the consumption of a part according to its geometry. Furthermore, this methodology will be extended to other materials for the three machines studied, and more models will be investigated in order to evaluate these processes with new indicators.

\section{Acknowledgment}

The authors would like to thanks Pierre Gabas, Julie Suzanne, Jules Woodcock and Jean-François Lemaire for their work on the data acquisition.

\section{References}

[1] Lee JY, An J, Chua CK, Fundamentals and applications of 3D printing for novel materials. Appl Mater Today, 7:120-133, 2017.

[2] Fahad M, Hopkinson N, Evaluation and comparison of geometrical accuracy of parts produced by sintering-based additive manufacturing processes. Int J Adv Manuf Technol 88(9-12): 3389-3394, 2017.

[3] Costabile G, Fera M, Fruggiero F, Lambiase A, Pham D, Cost models of additive manufacturing: a I iterature review. Int J Ind Eng Comput 8:263-282, 2017.

[4] Kellens, K, Baumers, M, Gutowski, T G., Flanagan, W, Lifset, R, Duflou, J, Environmental Dimensions of Additive Manufacturing: Mapping Application Domains and Their Environmental Implications. J of Ind Ecology $21: 49: 68,2017$.

[5] Luo, Y. L. Y., Ji, Z. J. Z., Leu, M. C. and Caudill, R, Environmental performance analysis of solid freedom fabrication processes, Proceedings of the 1999 IEEE International Symposium on Electronics and the Environment, 1999.

[6] Luo, Y., Leu, M. C. and Ji, Z, Assessment of environmental performance of rapid prototyping and rapid tooling processes, Solid Freeform Fabrication Symposium, pp. 783-792, 1999.

[7] Mognol, P., Lepicart, D. and Perry, N, Rapid prototyping: energy and environment in the spotlight, Rapid Prototyping Journal, 12 (1), pp. 26-34, 2006.

[8] Baumers, M., Tuck, C., Hague, R., Ashcroft, I. and Wildman, R, A comparative study of metallic additive manufacturing power consumption, Solid Freeform Fabrication Symposium, pp. 278-288. 2010.

[9] Baumers, M., Tuck, C., Wildman, R., Ashcroft, I. and Hague, R, Energy inputs to additive manufacturing: Does capacity utilization matter?, Solid Freeform Fabrication Symposium, pp. 30-40, 2010.

[10] Junk, S. and Côté, S, A practical approach to comparing energy effectiveness of rapid prototyping technologies, Proceedings of AEPR'12, (June), pp. 12-14 2009.

[11] Junk, S. and Côté, S, Influencing variables on sustainability in additive manufacturing. Offenburg Germany: Helena Bartolo, 2013.

[12] Sreenivasan, R. and Bourell, D. L, Sustainability study in selective laser sintering - An energy perspective, Solid Freeform Fabrication Symposium, pp. 257-265, 2009.

[13] Balogun, V. A., Kirkwood, N. D. and Mativenga, P. T, Direct Electrical Energy Demand in Fused Deposition Modelling, Procedia CIRP, 15, pp. 38-43, 2014.

[14] Le, V. T. and Paris, H, Impact of Total Build Height and Batch Size on Environmental Performance of Electron Beam Melting, Procedia CIRP. The Author(s), 69(May), pp. 112-117, 2018.

[15] Baumers, M., C. Tuck, R. Wildman, I. Ashcroft, E. Rosamond, and R. Hague, Transparency built-in. Energy consumption and cost estimation for additive manufacturing. Journal of Industrial Ecology 17(3): 4184312012. 
[16] Le Bourhis, F., O. Kerbrat, J.-Y. Hascoet, and P. Mognol, Sustain- able manufacturing: Evaluation and modeling of environmental impacts in additive manufacturing. The International Journal of Advanced Manufacturing Technology 69(9): 1927-1939, 2013.

[17] Xu, X., S. Meteyer,N. Perry, and Y. F. Zhao, Energy consumption model of binder-jetting AM processes. International Journal of Production Research, 2014.

[18] Kellens, K., E. Yasa, Renaldi, W. Dewulf, J. P. Kruth, and J. R. Duflou, Energy and resource efficiency of SLS/SLM processes. In Proceedings of the 22nd Solid Freeform Fabrication Symposium, 8-10 August, Austin, TX, USA, 1-16, 2011a

[19] Kellens, K., Renaldi, W. Dewulf, J. P. Kruth, and J. R. Duflou, Environmental impact modeling of selective laser sintering pro- cesses. Rapid Prototyping Journal 20(6): 459-470, 2014.

[20] M. Yosofi, O. Kerbrat, P. Mognol, Energy and material flow modelling of additive manufacturing processes, Virtual Phys. Prototyp. 2018, 13, 83.

[21] Yosofi, M.; Kerbrat, O.; Mognol, P. Additive manufacturing processes from an environmental point of view: A new methodology for combining technical, economic, and environmental predictive models. Int. J. Adv. Manuf. Technol. 2019, 102, 4073-4085.

[22] Motaparti KP, Taylor G, Leu MC, Chandrashekhara K, Castle J, Matlack M, Experimental investigation of effects of build parameters on flexural properties in fused deposition modelling parts. Virtual Phys Prototyp 12(3):207-220, 2017.

[23] Kim GD, Oh YT, A benchmark study on rapid prototyping processes and machines: quantitative comparisons of mechanical properties, accuracy, roughness, speed, and material cost. Proc Inst Mech Eng B J Eng Manuf 222(2):201-215, 2008.

[24] Byun HS, Lee KH, Determination of the optimal build direction for different rapid prototyping processes using multicriterion decision making. Robot Comput Integr Manuf 22(1):69- 80, 2006.

[25] Strano G, Hao L, Everson RM, Evans KE, Multi-objective optimization of selective laser sintering processes for surface quality and energy saving. Proc Inst Mech Eng B J Eng Manuf 225(9):1673-1682, 2007.

[26] Teitelbaum GA, Schmidt LC, Goaer Y, Examining potential design guidelines for use in fused deposition modeling to reduce build time and material volume. Int Des Eng Tech Conf Comput Inf Eng Conf 8:1-10, 2009.

[27] Kranz J, Herzog D, Emmelmann C, Design guidelines for laser additive manufacturing of lightweight structures in TiAl6V4. J Laser Appl 27(S14001):1-16, 2015.

[28] O. S. Carneiro, A. F. Silva, et R. Gomes, « Fused deposition modeling with polypropylene », Mater. Des., vol. 83, p. 768-776, oct. 2015,

[29] «Rayegani et Onwubolu - 2014 - Fused deposition modelling (FDM) process parameter.pdf».

[30] M. Montero, S. Roundy, D. Odell, S.-H. Ahn, et P. K. Wright, « Material Characterization of Fused Deposition Modeling (FDM) ABS by Designed Experiments », p. 21, 2001.

[31] M. Raju, M. K. Gupta, N. Bhanot, et V. S. Sharma, "A hybrid PSO- BFO evolutionary algorithm for optimization of fused deposition modelling process parameters », J. Intell. Manuf., vol. 30, no 7, p. 2743-2758, oct. 2019

[32] A. K. Sood, R. K. Ohdar, et S. S. Mahapatra, " Parametric appraisal of mechanical property of fused deposition modelling processed parts », Mater. Des., vol. 31, no 1, p. 287-295, janv. 2010

[33] Boschetto A, Giordano V, Veniali F, Modelling micro geometrical profiles in fused deposition process. Int J Adv Manuf Technol 61(9- 12):945-956, 2011.

[34] Boschetto A, Giordano V, Veniali F, Surface roughness prediction in fused depositionmodelling by neural networks. Int J Adv Manuf Technol 67(9-12):2727-2742, 2013.

[35] Hopkinson N, Dickens P, Analysis of rapid manufacturing - using layer manufacturing processes for production. Proc InstMech Eng Part C J Mech Eng Sci 217(1):31-40, 2003.

[36] BaumersM, Tuck C,Wildman R, Ashcroft, I., Rosamond E, Hague R, Combined build-time, energy consumption and cost estimation for direct metal laser sintering. Proc of the Solid Freeform Fabrication Symposium, Austin, USA, pp 278-288, 2012.

[37] Manogharan G, Wysk RA, Harrysson OLA, Additive manufacturing-integrated hybrid manufacturing and subtractive processes: economic model and analysis. Int J Comput Integr Manuf 29(5):473-488, 2016.

[38] Durgun I, Ertan R, Experimental investigation of FDM process for improvement ofmechanical properties and production cost. Rapid Prototyp J 20(3):228-23.5, 2016.

[39] C. Hodonou, O. Kerbrat, M. Balazinski1, M. Brochu, Process selection charts based on economy and environment: subtractive or additive manufacturing to produce structural components of aircraft. Int J Int des manuf. 14, 861-873, 2020. 
[40] Yosofi, M.; Kerbrat, O.; Mognol, P. Framework to Combine Technical, Economic and Environmental Points of View of Additive Manufacturing Processes. Procedia CIRP 2018, 69, 118-123.

[41] P. Shakor, S. Nejadi, S. Sutjipto, G. Paul, and N. Gowripalan, "Effects of deposition velocity in the presence/absence of E6-glass fibre on extrusion-based 3D printed mortar," Additive Manufacturing, vol. 32, p. 101069, 2020.

[42] P. Shakor, S. Nejadi, and G. Paul, "Investigation into the effect of delays between printed layers on the mechanical strength of inkjet 3DP mortar," Manufacturing Letters, vol. 23, pp. 19-22, 2020.

[43] P. Shakor, S. Nejadi, G. Paul, J. Sanjayan, and A. Nazari, "Mechanical properties of cement-based materials and effect of elevated temperature on three-dimensional (3-D) printed mortar specimens in inkjet 3-D printing," ACl Materials Journal, vol. 116, no. 2, pp. 55-67, 2019.

[44] P. Shakor, J. Sanjayan, A. Nazari, and S. Nejadi, "Modified 3D printed powder to cement-based material and mechanical properties of cement scaffold used in 3D printing," Construction and Building Materials, vol. 138, pp. 398-409, 2017.

[45] P. Shakor, J. Renneberg, S. Nejadi, and G. Paul, "Optimisation of different concrete mix designs for 3D Printing by utilising 6DOF industrial robot," in ISARC 2017-Proceedings of the 34th International Symposium on Automation and Robotics in Construction, 2017.

[46] P. Shakor, S. Nejadi, G. Paul, and S. Malek, "Review of emerging additive manufacturing technologies in $3 \mathrm{D}$ printing of cementitious materials in the construction industry," Frontiers in Built Environment, vol. 4, p. 85, 2019.

[47] P. Shakor, S. Nejadi, and G. Paul, "A study into the effect of different nozzles shapes and fibrereinforcement in 3D printed mortar," Materials, vol. 12, no. 10, p. 1708, 2019.

[48] F. Sartipi, "Automatic sorting of recycled aggregate using image processing and object detection," Journal of Construction Materials, vol. 1, pp. 3-3, 2020, doi: https://doi.org/10.36756/JCM.v1.2.1.

[49] T. Boulos, F. Sartipi, and K. Khoshaba, "Bibliometric analysis on the status quo of robotics in construction," Journal of Construction Materials, vol. 1, pp. 2-3, 2020.

[50] F. Sartipi and A. Sartipi, "Brief review on advancements in construction additive manufacturing," Journal of Construction Materials, vol. 1, pp. 2-4, 2020, doi: https://doi.org/10.36756/JCM.v1.2.4

[51] A. Gharizadeh, F. Sartipi, E. Ayoubi, and A. Severino, "The chemical reactor design configuration of CO2 concrete green solution," Journal of Construction Materials, vol. 1, pp. 2-5, 2020, doi: https://doi.org/10.36756/JCM.v1.2.5.

[52] F. Sartipi, "Preliminary structural design for extraterrestrial buildings," Journal of Construction Materials, vol. 2, pp. 2-3, 2021, doi: https://doi.org/10.36756/JCM.v2.2.3.

[53] F. Sartipi, K. Palaskar, A. Ergin, and U. Rajakaruna, "Viable construction technology for habitation on Mars: Fused Deposition Modelling," Journal of Construction Materials, vol. 1, no. 2, 2020, doi: https://doi.org/10.36756/JCM.v1.2.2.

[54] Y. Reches, "Concrete on Mars: Options, challenges, and solutions for binder-based construction on the Red Planet," Cement and Concrete Composites, vol. 104, p. 103349, 2019.

[55] F. Sanchez et al., "Development of nano-modified concrete for next generation of storage systems," Vanderbilt Univ., Nashville, TN (United States), 2018.

[56] Y. Reches, "A multi-scale review of the effects of gamma radiation on concrete," Results in Materials, vol. 2, p. 100039, 2019.

[57] Y. Reches, "Quantification and modeling of the interactions of gamma radiation with concrete from bulkscale observations," International Journal of Concrete Structures and Materials, vol. 13, no. 1, pp. 1-8, 2019.

[58] G. G. Deichert, K. D. Linton, K. A. Terrani, A. P. Selby, and Y. Reches, "Vanderbilt University Gamma Irradiation of Nano-modified Concrete (2017 Milestone Report)," Oak Ridge National Lab.(ORNL), Oak Ridge, TN (United States), 2017.

[59] F. Sartipi, "Influence of $5 \mathrm{G}$ and IoT in construction and demolition waste recycling-conceptual smart city design," Journal of Construction Materials, vol. 1, pp. 4-1, 2020, doi: https://doi.org/10.36756/JCM.v1.4.1.

[60] F. Sartipi, "Organizational structure of construction entities based on the cooperative game theory," Journal of Construction Materials, vol. 1, no. 2, 2020, doi: https://doi.org/10.36756/JCM.v1.3.3

[61] J. Luliano, A. Singh, and F. Sartipi, "Political-economical evaluation of CO2 capture in Australian building sector," Journal of Construction Materials, vol. 1, pp. 3-2, 2020, doi: https://doi.org/10.36756/JCM.v1.3.2.

[62] F. Sartipi, "Publicizing construction firms by cryptocurrency," Journal of Construction Materials, vol. 2, pp. 3-1, 2021, doi: https://doi.org/10.36756/JCM.v2.3.1. 
[63] M. C. Liem and P. Tze, "A Comparison Study of Indonesia and China: Macroeconomics Performance and Bank Soundness Performance," JAAF (Journal of Applied Accounting and Finance), vol. 1, no. 2, pp. 147157, 2017.

[64] M. C. Liem, "Corporate Governance in Banking Industry: An Explanatory Study," Corporate Governance, vol. 7, no. 6, 2016.

[65] X. Yan et al., "High-content imaging-based pooled CRISPR screens in mammalian cells," Journal of Cell Biology, vol. 220, no. 2, 2021.

[66] M. C. Liem and E. Yosua, "Innovative Entrepreneurial Education for International Hospitality and Tourism Business (IHTB)," GSTF Journal on Business Review (GBR), vol. 2, no. 3, 2013.

[67] M. C. LIEM, "Islamic banking and corporate governance," Qualitative and Quantitative Research Review, vol. 1, no. 1, 2016. 